\title{
Regulation by Magnesium of Potato Tuber Mitochondrial Respiratory Activities
}

\author{
Joaquim A. F. Vicente, ${ }^{1,4}$ Vítor M. C. Madeira, ${ }^{2}$ and Anibal E. Vercesi ${ }^{3}$
}

Received July 27, 2004; accepted September 22, 2004

Dehydrogenase activities of potato tuber mitochondria and corresponding phosphorylation rates were measured for the dependence on external and mitochondrial matrix $\mathrm{Mg}^{2+}$. Magnesium stimulated state 3 and state 4 respiration, with significantly different concentrations of matrix $\mathrm{Mg}^{2+}$ required for optimal activities of the several substrates. Maximal stimulation of respiration with all substrates was obtained at 2-mM external $\mathrm{Mg}^{2+}$. However, respiration of malate, citrate, and $\alpha$-ketoglutarate requires at least 4-mM $\mathrm{Mg}^{2+}$ inside mitochondria for maximization of dehydrogenase activities. The phosphorylation system, requires a low level of internal $\mathrm{Mg}^{2+}(0.25 \mathrm{mM})$ to reach high activity, as judged by succinate-dependent respiration. However, mitochondria respiring on citrate or $\alpha$-ketoglutarate only sustain high levels of phosphorylation with at least 4-mM matrix $\mathrm{Mg}^{2+}$. Respiration of succinate is active without external and matrix $\mathrm{Mg}^{2+}$, although stimulated by the cation. Respiration of $\alpha$-ketoglutarate was strictly dependent on external $\mathrm{Mg}^{2+}$ required for substrate transport into mitochondria, and internal $\mathrm{Mg}^{2+}$ is required for dehydrogenase activity. Respiration of citrate and malate also depend on internal $\mathrm{Mg}^{2+}$ but, unlike $\alpha$-ketoglutarate, some activity still remains without external $\mathrm{Mg}^{2+}$. All the substrates revealed insensitive to external and internal mitochondrial $\mathrm{Ca}^{2+}$, except the exogenous NADH dehydrogenase, which requires either external $\mathrm{Ca}^{2+}$ or $\mathrm{Mg}^{2+}$ for detectable activity. Calcium is more efficient than $\mathrm{Mg}^{2+}$, both having cumulative stimulation. Unlike $\mathrm{Ca}^{2+}, \mathrm{Mn}^{2+}$ could substitute for $\mathrm{Mg}^{2+}$, before and after addition of $\mathrm{A} 23$, showing its ability to regulate phosphorylation and succinate dehydrogenase activities, with almost the same efficiency as $\mathrm{Mg}^{2+}$.

KEY WORDS: Magnesium regulation; plant mitochondria; mitochondrial respiration; A23187 mitochondrial $\mathrm{Mg}^{2+}$ depletion.

\section{INTRODUCTION}

Magnesium is an essential divalent cation for regulation of several life activities in cells. Most of the free $\mathrm{Mg}^{2+}$ is cytosolic and a small part is inside organelles, the majority being bound to proteins and metabolites (Corkey et al., 1986; Flatman, 1984). Some information is available on the regulatory action of $\mathrm{Mg}^{2+}$ for mitochondrial

\footnotetext{
${ }^{1}$ Departamento de Botânica, Universidade de Coimbra, Coimbra, Portugal.

${ }^{2}$ Departamento de Bioquímica da Faculdade de Ciências e Tecnologia, Universidade de Coimbra, Coimbra, Portugal.

${ }^{3}$ Departamento de Patologia Clínica, Faculdade de Ciências Médicas, Universidade Estadual de Campinas, Campinas, SP, Brasil.

${ }^{4}$ To whom correspondence should be addressed at Departamento de Zoologia, FCT, Universidade de Coimbra, 3004-517 Coimbra, Portugal; e-mail: jvicente@ci.uc.pt.
}

dehydrogenases in animal tissues, mainly in isolated enzymes (Bedino and Testore, 1992; Bowman and Ikuma, 1976; McCormack and Denton, 1979; Panov and Scarpa, 1996a; Thomas et al., 1986).

The biochemical role of $\mathrm{Mg}^{2+}$, in addition to $\mathrm{Ca}^{2+}$, concerning mitochondrial activities, is assigned to the control of dehydrogenases (Moravec and Bond, 1991, 1992). Mitochondrial free $\left[\mathrm{Mg}^{2+}\right]$ reversibly changes during the transition of respiration from stage 4 to stage 3 (Jung et al., 1997). It plays a central role to the mitochondrial metabolism by modulating enzyme activities (Coultate and Dennis, 1969) and on the transport of anions (Beavis and Garlid, 1987; Beavis and Vercesi, 1992) and cations (Bernardi, 1999). However, the regulation of cell $\mathrm{Mg}^{2+}$ is far less understood than other ions as $\mathrm{Ca}^{2+}, \mathrm{K}^{+}, \mathrm{Cl}^{-}$, and $\mathrm{H}^{+}$. ATP-synthase (ATPase) activities are strictly dependent on the presence of $\mathrm{Mg}^{2+}$ in the mitochondrial matrix 
(Bulygin et al., 1993; Gómez-Puyou et al., 1983). Mitochondria store $\mathrm{Mg}^{2+}$ that can be rapidly mobilized to assist several metabolic processes (Romani et al., 1991, 1993).

In this work, we investigated the regulatory role of $\mathrm{Mg}^{2+}$, inside and outside potato tuber mitochondria, on the respiratory activities elicited by specific substrates. We analyzed the involvement of $\mathrm{Mg}^{2+}$ as a potential modulator of potato tuber mitochondrial respiration, since scarce studies on this area, with similar methodologies and/or purposes, only used animal mitochondria (Panov and Scarpa, 1996b; Pfeiffer et al., 1974; Reed and Lardy, 1972; Thomas et al., 1986). The divalent cation ionophore A23187 (A23) was used as a tool for depletion of mitochondrial matrix $\mathrm{Mg}^{2+}$, permitting the control of its concentration (Panov and Scarpa, 1996b; Pfeiffer et al., 1974; Reed and Lardy, 1972). In these cases, the $\mathrm{Ca}^{2+}$ transmembrane movements render difficult the evaluation of the $\mathrm{Mg}^{2+}$ regulatory role. In advantage, potato tuber mitochondria are devoid of $\mathrm{Ca}^{2+}$ movements, thus yielding clear data and conclusions. As a complement, $\mathrm{Ca}^{2+}$ and $\mathrm{Mn}^{2+}$ were investigated as putative replacers for $\mathrm{Mg}^{2+}$ in particular activities of respiration.

\section{MATERIALS AND METHODS}

\section{Preparation of Mitochondria}

Fresh potato tubers (Solanum tuberosum L.) were obtained from the local market. Mitochondria were isolated and purified according to a procedure involving Percoll gradient centrifugation as a terminal purification step (Neuburger et al., 1982). The mitochondrial fraction was collected from the Percoll gradient with a Pasteur pipette and washed twice, by centrifugation, at $30000 \times g$ for $5 \mathrm{~min}$ in washing medium (medium A) containing 250-mM mannitol, $0.1 \%$ BSA, and 10-mM Hepes (pH 7.2). The pellet was gently resuspended in medium $A$, at a protein concentration of $20-30 \mathrm{mg} / \mathrm{mL}$. Protein was determined by the procedure of Bradford (Bradford, 1976) calibrated with bovine serum albumin standards.

\section{Measurement of Respiratory Activities}

Oxygen consumption was monitored with a Clark oxygen electrode, at $25^{\circ} \mathrm{C}$. The polarographic measurements were performed in $1.5-\mathrm{mL}$ reaction medium (medium B) containing 0.25-M sucrose, 10-mM Hepes (pH 7.2), 20- $\mathrm{mM} \mathrm{KCl}, 2-\mathrm{mM} \mathrm{K}_{2} \mathrm{HPO}_{4}$, and $0.05 \%$ BSA. We always added 0.2-mM ATP to the reaction medium for assays of all the substrates, $0.5-\mathrm{mM} \mathrm{NAD}^{+}$and thiamine pyrophospate for citrate, malate, and $\alpha$-ketoglutarate, and also $100-\mu \mathrm{M}$ ADP only for assays with $\alpha$-ketoglutarate (Bowman and Ikuma, 1976; Coultate and Dennis, 1969; Soole et al., 1990). The divalent cations, in the form of chloride salts, were added at the concentrations referred in the figures of legends. State 3 was elicited by adding $\mathrm{ADP}$, and uncoupled respiration by adding $1-\mu \mathrm{M}$ FCCP or $75 \mathrm{ng} / \mathrm{mL}$ valinomycin. Respiration rates were calculated assuming an oxygen concentration of $250 \mathrm{nmol} \mathrm{O}_{2} / \mathrm{mL}$ of experimental medium at $25^{\circ} \mathrm{C}$.

The mitochondrial transmembrane electric potential $(\Delta \psi)$ was monitored with a $\mathrm{TPP}^{+}$-electrode (Kamo et al., 1979). All experiments were carried out in an opened vessel at $25^{\circ} \mathrm{C}$, with efficient magnetic stirring in $1 \mathrm{~mL}$ of medium B, supplemented with $3-\mu \mathrm{M} \mathrm{TPP}^{+}$. About $0.3-$ $0.45 \mathrm{mg} / \mathrm{mL}$ of mitochondrial protein were used in the reaction medium supplemented with the additions indicated in the legends of the figures. Membrane potential was calculated using the equation of Kamo et al. (Kamo et al., 1979) where the deflection of the $\mathrm{TPP}^{+}$-electrode potential $(\Delta E)$ was determined according to the size of the trace collapsed as a consequence of valinomycin-induced $\mathrm{K}^{+}$diffusion, by using $75 \mathrm{ng} / \mathrm{mL}$ valinomycin at the end of each assay.

\section{Mitochondrial Swelling}

Mitochondrial osmotic volume changes were estimated from decrease in the absorbance at $520 \mathrm{~nm}$ with a suitable spectrophotometer-recorder set up (Beavis and Vercesi, 1992). Mitochondria $(0.5-0.75 \mathrm{mg})$ were suspended in $2.5 \mathrm{~mL}$ of hypoosmotic sulphate medium (50-mM sulphate, 5-mM Hepes-pH 7.1, 0.1-mM EDTA, and 0.1-mM EGTA) supplemented with 0.1\% BSA, 0.2$\mathrm{mM}$ ATP, 0.5 -mM NAD ${ }^{+}, 0.5$-mM thiamine pyrophosphate, at $30^{\circ} \mathrm{C}$.

\section{RESULTS AND DISCUSSION}

\section{An Overview of Respiration Control by $\mathbf{M g}^{2+}$}

Using potato tuber mitochondrial fractions, by adding exogenous $\mathrm{Mg}^{2+}$, activities of state 3 and state 4 succinate-elicited respiration were maximal at $2-\mathrm{mM}$ $\mathrm{Mg}^{2+}$, like with other respiratory substrates (Fig. 1). In the absence of external $\mathrm{Mg}^{2+}$ (0.5-mM EDTA), state 4 and state 3 activities are depressed (30-60\%) for respiration dependent on succinate, exogenous NADH-Ca ${ }^{2+}$, malate and citrate, and no activity was detected for $\alpha$ ketoglutarate-dependent respiration (Fig. 1), suggesting that $\alpha$-ketoglutarate transport depends on external $\mathrm{Mg}^{2+}$, at variance with the transport of the other substrates. 


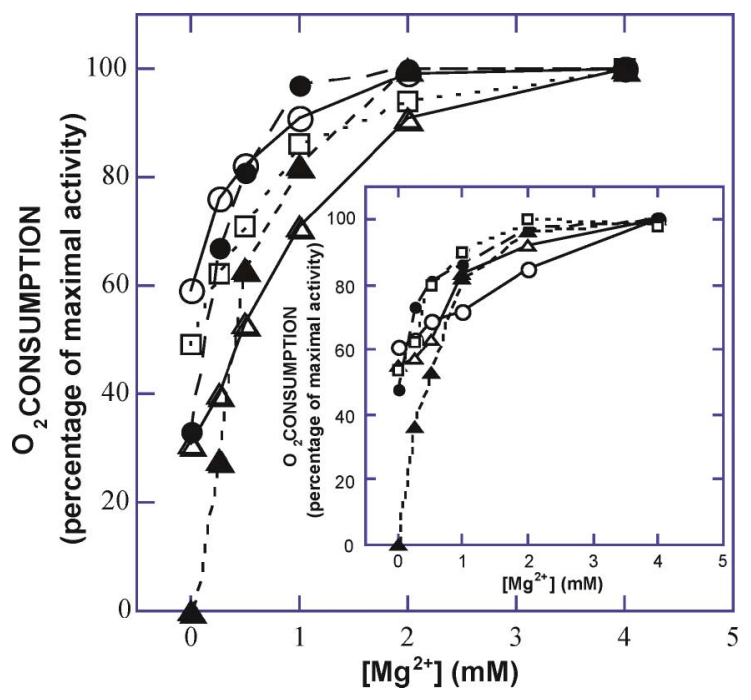

Fig. 1. Effect of external $\mathrm{Mg}^{2+}$ on mitochondrial state 3 respiration of several substrates. Oxygen consumption by mitochondria $(0.2-$ $0.3 \mathrm{mg} / \mathrm{mL}$ ) in reaction medium containing $250-\mathrm{mM}$ sucrose, $10-\mathrm{mM}$ Hepes (pH 7.2), $20-\mathrm{mM} \mathrm{KCl}, 2-\mathrm{mM} \mathrm{K}_{2} \mathrm{HPO}_{4}, 0.05 \%$ BSA, 0.2-mM ATP. Succinate $(\circ)$, NADH $(\Delta)$, Malate $(\bullet), \alpha$-ketuglutarate $(\boldsymbol{\Delta})$, and citrate $(\square)$. Media were supplemented with $0.5-\mathrm{mM} \mathrm{NAD}^{+}$plus $0.5-\mathrm{mM}$ thiamine pyrophosphate for citrate, malate, and $\alpha$-ketoglutarate, and also $100-\mu \mathrm{M}$ ADP only for assays with $\alpha$-ketoglutarate. Maximal activities corresponding to $100 \%$, expressed in nmol $\mathrm{O}_{2} \cdot \mathrm{mg}$ protein ${ }^{-1} \cdot \mathrm{min}^{-1}$ $( \pm \mathrm{SD})$ in state 3 for: succinate $(5 \mathrm{mM}), 175( \pm 2)$; NADH-Ca ${ }^{2+}(2-$ $0.05 \mathrm{mM}), 213( \pm 6)$; malate $(20 \mathrm{mM}), 89( \pm 4) ; \alpha$-ketoglutarate $(2 \mathrm{mM})$, $92( \pm 9)$; citrate $(4 \mathrm{mM}), 49( \pm 4)$. Inset: state 4 respiration with: succinate, $58( \pm 14)$; NADH-Ca ${ }^{2+}(2-0.05 \mathrm{mM}), 46( \pm 6)$; malate $(20 \mathrm{mM})$, $31( \pm 2) ; \alpha$-ketoglutarate $(2 \mathrm{mM}), 24( \pm 3)$; citrate $(4 \mathrm{mM}), 16( \pm 4)$. Values are means from at least three independent experiments with three replicates per experiment.

Mitochondria were treated with A23, an ionophore specific for divalent cations, making it possible to appreciate the effect on respiration of divalent cations depletion from the mitochondrial matrix. In the presence of A23 $(1 \mu \mathrm{M})$, endogenous mitochondrial $\mathrm{Mg}^{2+}$ and $\mathrm{Ca}^{2+}$ concentrations equilibrate with the external medium (Panov and Scarpa, 1996b; Pfeiffer et al., 1974; Reed and Lardy, 1972). Thus, internal $\mathrm{Mg}^{2+}$ is virtually identical to the added concentration in the reaction medium. The endogenous mitochondrial $\mathrm{Mg}^{2+}$ moved to the medium is neglected since the mitochondrial volume is negligible as compared with the volume of assay medium (matrix and assay volumes ratio is about $1 / 4500$ ).

Activities of all the respiratory substrates were stimulated by internal $\mathrm{Mg}^{2+}$ (A23 present), with a higher dependence for substrates of Complex I respiration (malate, citrate, and $\alpha$-ketoglutarate), all being completely inactive in the absence of added $\mathrm{Mg}^{2+}$ (Fig. 2). They required at least $4-\mathrm{mM} \mathrm{Mg}^{2+}$ for maximal activities, similar with those obtained without $\mathrm{A} 23$, suggesting that intrinsic $\mathrm{Mg}^{2+}$ is at

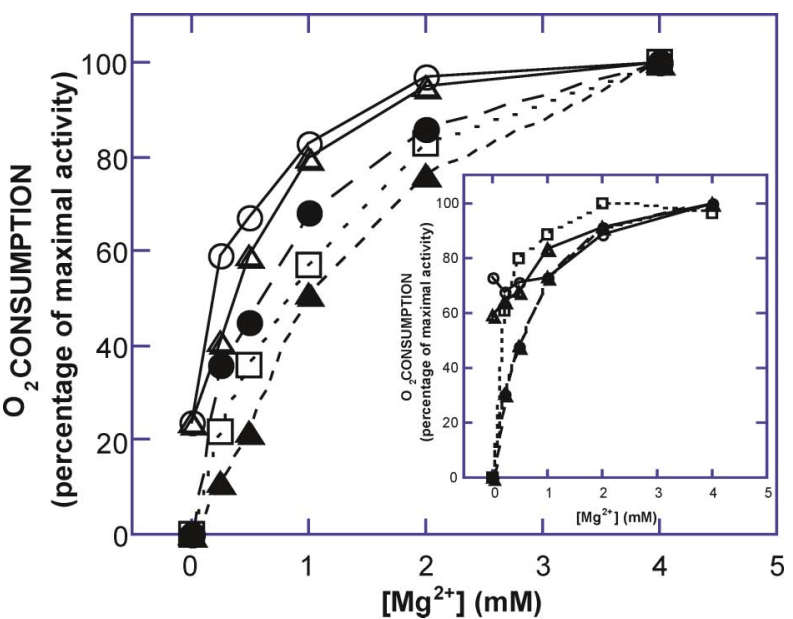

Fig. 2. Effect of mitochondrial matrix $\mathrm{Mg}^{2+}$ on state 3 respiration of several substrates. Oxygen consumption by mitochondria $(0.2-0.3 \mathrm{mg} / \mathrm{mL})$ in conditions indicated in Fig. 1, after A23187 $(1 \mu \mathrm{M})$ addition. Succinate $(\circ)$, NADH $(\Delta)$, Malate $(\bullet), \alpha$-ketuglutarate $(\boldsymbol{\Delta})$, and citrate $(\square)$. Maximal activities corresponding to $100 \%$, expressed in $\mathrm{nmol} \mathrm{O}_{2}$. $\mathrm{mg}$ protein ${ }^{-1} \cdot \min ^{-1}( \pm \mathrm{SD})$ in state 3 for: succinate $(5 \mathrm{mM}), 175( \pm 8)$; NADHCa $(2-0.05 \mathrm{mM}), 212( \pm 5)$; malate $(20 \mathrm{mM}), 92( \pm 6) ; \alpha$-ketoglutarate $(2 \mathrm{mM}), 97( \pm 8)$; citrate $(4 \mathrm{mM}), 51( \pm 5)$. Inset: results for state 4 respiration with: succinate, $58( \pm 12)$; NADH-Ca ${ }^{2+}(2-0.05 \mathrm{mM}), 47( \pm 5)$; malate $(20 \mathrm{mM}), 35( \pm 1) ; \alpha$-ketoglutarate $(2 \mathrm{mM}), 22( \pm 2)$; citrate $(4 \mathrm{mM}), 16( \pm 4)$. Values are means from at least three independent experiments with three replicates per experiment.

this range in native mitochondria. As succinate and exogenous NADH-dependent activities still remain at about $30 \%$ without added $\mathrm{Mg}^{2+}$ (plus A23), we conclude that these activities are not completely dependent on $\mathrm{Mg}^{2+}$ although stimulated by it.

Potato tuber mitochondrial state 4 respiration of succinate (with or without oligomycin $1 \mu \mathrm{g} / \mathrm{mL}$ ) improved by $\mathrm{Mg}^{2+}$ (Figs. 1 and 2, insets), in contrast with the results observed for succinate-dependent respiration of rat skeletal-muscle mitochondria, where $\mathrm{Mg}^{2+}$, decreasing proton conductance, inhibits state $4 \mathrm{O}_{2}$ consumption (Cadenas and Brand, 2000).

\section{The Dependence of $\alpha$-Ketoglutarate-Dependent Respiration on $\mathrm{Mg}^{2+}$}

The dependence on external $\mathrm{Mg}^{2+}$ of $\alpha$-ketoglutarate transport into the mitochondria was checked by hypoosmotic swelling in sulphate medium. Without $\mathrm{Mg}^{2+}$, no significant swelling was elicited by $\alpha$-ketoglutarate addition (Fig. 3(A)). However, significant swelling of respiring mitochondria, due to $\alpha$-ketoglutarate entry, occurs with $\mathrm{Mg}^{2+}(2-4 \mathrm{mM})$ in medium (Fig. 3(A)). In contrast, swellings elicited by malate or citrate (Fig. 3(B) 


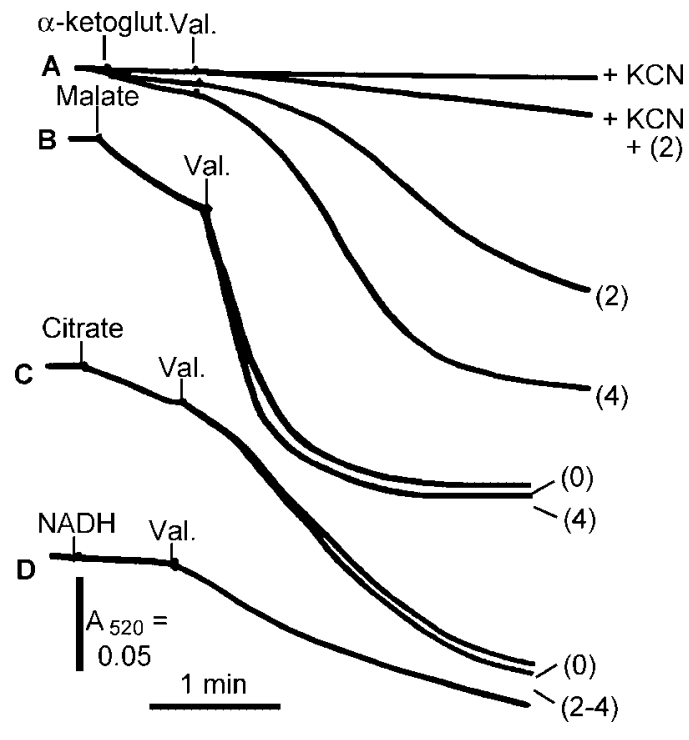

Fig. 3. Effect of $\mathrm{Mg}^{2+}$ on the mitochondrial swelling induced by substrate entry. Swelling in hypoosmotic $\mathrm{K}^{+}$-sulphate medium $(\mathrm{pH} 7.1$ ) supplemented with $0.1 \%$ BSA, 0.2-mM ATP, 0.5-mM NAD ${ }^{+}, 0.5-\mathrm{mM}$ thiamine pyrophosphate, and the respiratory substrate as indicated. A, $\alpha$-ketoglutarate $(10 \mathrm{mM}) . \mathrm{B}$, malate $(10 \mathrm{mM})$. C, citrate $(10 \mathrm{mM})$. D, NADH $(2 \mathrm{mM})$. Numbers in parentheses state for $\mathrm{Mg}^{2+}$ concentrations $(\mathrm{mM}) .+\mathrm{KCN}$, incubation with $0.2-\mathrm{mM} \mathrm{KCN}$. Val., addition of $1-\mu \mathrm{M}$ valinomycin. Curves are representative of a group of at least four independent experiments.

and (C)) occur without added $\mathrm{Mg}^{2+}$, ascertaining that these substrates, unlike $\alpha$-ketoglutarate, are not strictly dependent on external $\mathrm{Mg}^{2+}$ for the transport into the matrix where they are oxidized. In Fig. 3(A), inhibition of $\alpha$-ketoglutarate-dependent respiration by $\mathrm{KCN}(0.2 \mathrm{mM})$ blocks the entry of substrate avoiding swelling. This behavior is also observed with the other substrates (Fig. 3), ascertaining that the uptake of these substrates requires energization. Sulphate medium is experimentally appropriate for these swelling studies, since plant energized mitochondria (respiring exogenous NADH, which is not transported into the matrix) are almost impermeable to sulphate (Fig. 3(D)). Therefore, valinomycin-induced swelling after addition of the respiratory substrates is mainly due to the entry of each added substrate.

Internal mitochondrial $\mathrm{Mg}^{2+}$ is required at higher concentrations than external $\mathrm{Mg}^{2+}$ (Fig. 4). The maximal value of about $200 \mathrm{nmol} \mathrm{O}_{2} . \mathrm{mg}$ protein ${ }^{-1}$. $\mathrm{min}^{-1}$ is obtained at about 2-mM external and/or internal mitochondrial $\mathrm{Mg}^{2+}$ for succinate respiration, but other substrates require $4-\mathrm{mM} \mathrm{Mg}^{2+}$ inside mitochondria (A23 present) to reach the maximal activities, namely for $\alpha$-ketoglutarate (about $95 \mathrm{nmol} \mathrm{O}_{2}$. $\mathrm{mg}$ protein ${ }^{-1} \cdot \mathrm{min}^{-1}$ ). With $0.5-\mathrm{mM} \mathrm{Mg}^{2+}$ added, strong inhibition of $\alpha$-ketoglutaratedependent state $3(61 \%)$ and uncoupled respiration $(65 \%)$

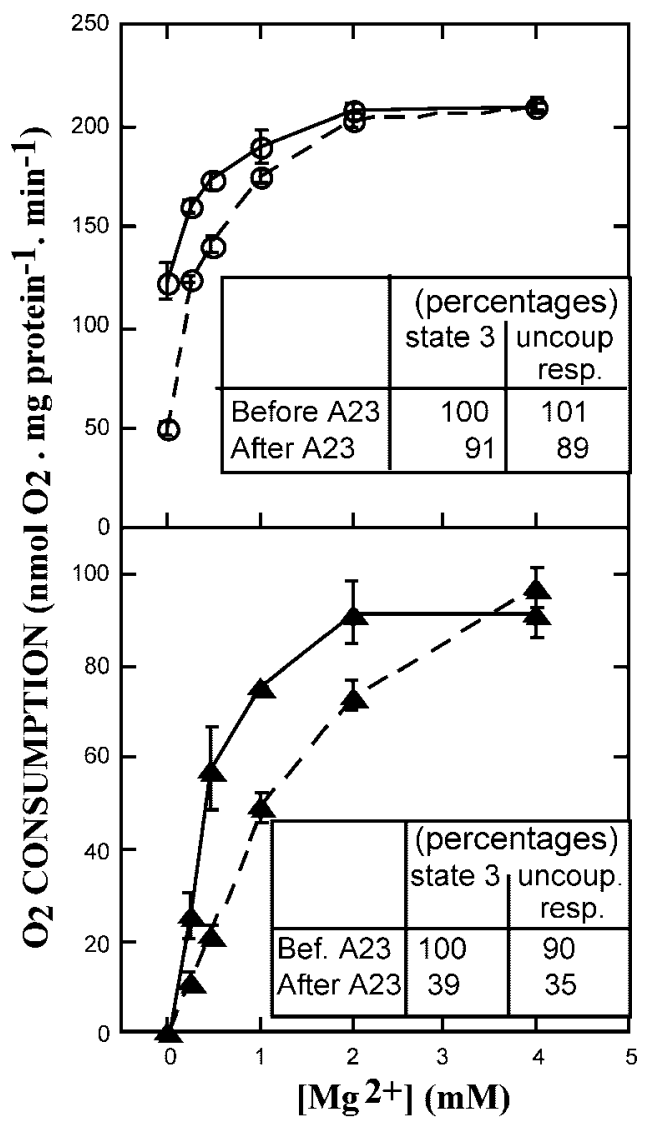

Fig. 4. Comparative analyses of stimulation by $\mathrm{Mg}^{2+}$ of succinate (upper) and $\alpha$-ketoglutarate (lower) state 3 respiration, before and after A23 addition. Oxygen consumption by potato tuber mitochondria $(0.2-0.3 \mathrm{mg} / \mathrm{mL})$ in the conditions indicated in Fig. 1. Full lines, without A23 (external $\mathrm{Mg}^{2+}$ ); dashed lines, with 1- $\mu \mathrm{M}$ A23 (internal $\mathrm{Mg}^{2+}$ ). Insets: Percentages of activities with $0.5-\mathrm{mM} \mathrm{Mg}^{2+}$, in state 3 and uncoupled respiration before and after A23 addition. Activities corresponding to $100 \%$, expressed in $\mathrm{nmol} \mathrm{O}_{2}$. $\mathrm{mg}$ protein ${ }^{-1} \cdot \mathrm{min}^{-1}( \pm \mathrm{SD})$ : for succinate, $175 \pm 8$; for $\alpha$-ketoglutarate, $58 \pm 9$. Values are means \pm SEM from at least four independent experiments.

occurred by A23 addition (Fig. 4, inset), in contrast with succinate-dependent respiration, where both activities were only slightly inhibited (about $10 \%$ ). Therefore, a significantly higher internal $\mathrm{Mg}^{2+}$ concentration is required for maximal activity of $\alpha$-ketoglutarate dehydrogenase than for succinate dehydrogenase.

\section{The Dependence of Citrate-Dependent Respiration on $\mathrm{Mg}^{2+}$}

At $0.1-\mathrm{mM} \mathrm{Mg}^{2+}$, the succinate-dependent phosphorylation rate $(540 \mathrm{nmol}$ ADP phosphorylated. mg protein $\left.^{-1} \cdot \min ^{-1}\right)$ decreased more than $50 \%$ by A23 addition (Fig. 5). As succinate uncoupled respiration 


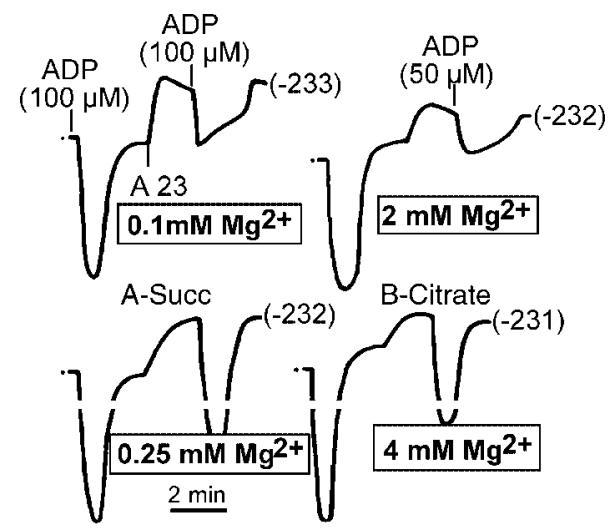

Fig. 5. Effect of A23 on the phosphorylation rates of potato tuber mitochondria respiring succinate (A) and citrate (B) as a function of $\mathrm{Mg}^{2+}$. Records produced by a $\mathrm{TPP}^{+}$-electrode system of $\Delta \psi$ elicited by mitochondria respiring succinate (succ) and citrate. Assays were performed as indicated in Fig. 1, plus 3- $\mu \mathrm{M} \mathrm{TPP}^{+}$. Record of each experiment was performed at the $\mathrm{Mg}^{2+}$ concentration expressed in a box, and numbers within parentheses state $\Delta \psi$ values in $\mathrm{mV}$. A23, addition of $1 \mu \mathrm{M}$ A23187.

(142 nmol $\mathrm{O}_{2}$. mg protein ${ }^{-1} \cdot \min ^{-1}$ ) was significantly higher than state 3 respiration $\left(87 \mathrm{nmol} \mathrm{O}_{2} . \mathrm{mg}_{\text {protein }}{ }^{-1}\right.$. $\mathrm{min}^{-1}$ ), this indicates that the phosphorylation system itself is the limiting step of succinate dehydrogenase activity in state 3 , with $0.1-\mathrm{mM} \mathrm{Mg}^{2+}$ inside mitochondria. For concentrations of at least $0.25-\mathrm{mM} \mathrm{Mg}^{2+}$, state 3 and uncoupled succinate-dependent respiration activities exhibit similar values. In agreement with state 3 succinatedependent $\mathrm{O}_{2}$ consumption expressed in Fig. 1 , the $\mathrm{TPP}^{+}-$ electrode records (Fig. 5) indicate that 0.25 - mM external $\mathrm{Mg}^{2+}$ induces a high level of phosphorylation rate (612 nmol ADP phosphorylated. mg protein ${ }^{-1} \cdot \min ^{-1}$ ), which is not significantly affected by A23 addition.

On the other hand, the maximal citrate-dependent phosphorylation rate (192 nmol ADP phosphorylated. mg protein ${ }^{-1} \cdot \mathrm{min}^{-1}$, with $4-\mathrm{mM} \mathrm{Mg}^{2+}$ ) is considerably lower than succinate-dependent phosphorylation rate in the presence of $0.25-\mathrm{mM} \mathrm{Mg}^{2+}$ (Fig. 5). This is not due to the level of $\Delta \psi$, since both substrates, citrate and succinate, elicited a similar $\Delta \psi$ (about $-232 \mathrm{mV}$ ). After A23 addition, citrate-dependent phosphorylation rate decreases at less than 4-mM Mg${ }^{2+}$. The phosphorylation system, common to respiration with all the substrates, is not the limiting step of the citrate-dependent phosphorylation. This indicates that optimal activities of citrate-dependent respiration require 4-mM internal $\mathrm{Mg}^{2+}$ and this concentration is putatively sequestered into native potato tuber mitochondria. Therefore, high $\mathrm{Mg}^{2+}$ concentrations (at least $4 \mathrm{mM}$ ) are required inside mitochondria for maximal citrate dehydrogenase activity, rather than for the phosphorylation system itself.

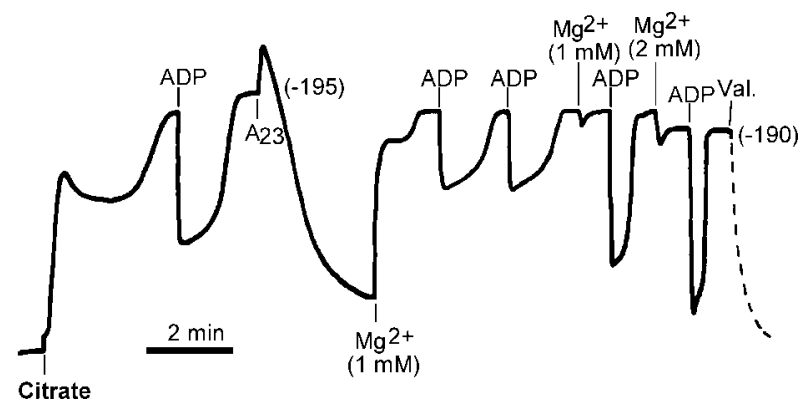

Fig. 6. Recovering of maximal citrate-dependent activity by $\mathrm{Mg}^{2+}$ after inhibition by A23. The assay was performed as described in Fig. 5, using reaction medium without $\mathrm{Mg}^{2+}$. ADP, ADP $50 \mu \mathrm{M}$; Val.,valinomycin $1 \mu \mathrm{M}$; A23, A23187 $1 \mu \mathrm{M}$. Numbers within parentheses state $\Delta \psi$ values in $\mathrm{mV}$. Record representative of a group of four independent experiments.

As already observed (Fig. 2), mitochondrial matrix $\mathrm{Mg}^{2+}$ is essential for activities of dehydrogenases of the referred TCA cycle intermediates (Bowman and Ikuma, 1976; Coultate and Dennis, 1969; Panov and Scarpa, 1996b; Tobin et al., 1980). It is known that the phosphorylation system requires internal mitochondrial $\mathrm{Mg}^{2+}$ (Bulygin et al., 1993; Gómez-Puyou et al., 1983). However, results in Fig. 5 revealed that significantly lower internal $\mathrm{Mg}^{2+}(0.25 \mathrm{mM})$ is required for high phosphorylation than for high citrate dehydrogenase activity (4 mM), like with $\alpha$-ketoglutarate respiration activity (Fig. 4).

In Fig. 6, we clearly observe that plant mitochondria respiring citrate develop $\Delta \psi(-195 \mathrm{mV})$ and phosphorylate ADP in the absence of external $\mathrm{Mg}^{2+}$. However, addition of A23 induces fast dissipation of $\Delta \psi$ as a consequence of inhibition of citrate-dependent respiration (Fig. 2), resulting from internal $\mathrm{Mg}^{2+}$ efflux induced by A23. We observed that this inhibition is reversed by adding $1-\mathrm{mM} \mathrm{Mg}^{2+}$, recovering $\Delta \psi(-190 \mathrm{mV})$ and phosphorylation capacity. Furthermore, second and third additions of $1 \mathrm{mM}$ and then 2- $\mathrm{mM} \mathrm{Mg}^{2+}$ both increased phosphorylation efficiency (Fig. 6). Similar results can be obtained using malate instead of citrate.

Maximal activity succeeded with at least 4-mM $\mathrm{Mg}^{2+}$ added, as was already detected. This shows that A23 only depletes mitochondrial $\mathrm{Mg}^{2+}$, in exchange for protons (Panov and Scarpa, 1996b; Pfeiffer et al., 1974; Reed and Lardy, 1972). No direct inhibitory action on respiration of citrate, like any other substrate, was detected by us, in contrast with observations in animal mitochondria for $\alpha$-ketoglutarate or pyruvate dehydrogenases (Panov and Scarpa, 1996b). These discrepancies are most probably a consequence of differences in the experimental conditions. 


\section{Control of Respiration by Divalent Cations Other Than $\mathrm{Mg}^{2+}$}

It has been ascertained if $\mathrm{Mg}^{2+}$ could be replaced for the most common divalent cations, namely $\mathrm{Ca}^{2+}$ and $\mathrm{Mn}^{2+}$. Successful replacements will relate with ATPsynthase activity and mitochondrial respiration-dependent dehydrogenases.

Because A23 equilibrates external and internal mitochondrial free $\mathrm{Ca}^{2+}$ and $\mathrm{Mg}^{2+}$ (Panov and Scarpa, 1996b; Reed and Lardy, 1972), one effect on the mitochondrial respiration could be accounted for by different sensitivities of the dehydrogenases to both or either of the divalent cations. However, addition of $\mathrm{Mg}^{2+}$, but not $\mathrm{Ca}^{2+}$, totally recovers dehydrogenase activities of all the tested substrates, except for exogenous NADH dehydrogenase (Soole et al., 1990), an enzyme not known in animal mitochondria, that is sensitive to external $\mathrm{Ca}^{2+}$ after $\mathrm{Mg}^{2+}$.

Exogenous NADH dehydrogenase activity (Table I) is higher with $\mathrm{Ca}^{2+}(67 \%)$ than with $\mathrm{Mg}^{2+}(30 \%)$, and is the only respiratory activity where cumulative stimulatory action was clearly achieved by adding $\mathrm{Mg}^{2+}$ and $\mathrm{Ca}^{2+}(87 \%)$. However, this is a regulation occurring in the absence of A23, meaning dependence on divalent outer anions.

Succinate-dependent respiration, evaluated by $\Delta \psi$ estimation with the $\mathrm{TPP}^{+}$-electrode (Fig. 7) shows that, in the absence of added divalent cations, A23 induces $\Delta \psi$ increase as a result of internal $\mathrm{Mg}^{2+}$ exchange by external protons, converting the $\Delta \mathrm{pH}$ component into $\Delta \psi\left(\mathrm{TPP}^{+}\right.$-

Table I. Control of the Divalent Cations $\mathrm{Mg}^{2+}$ and $\mathrm{Ca}^{2+}$ on the Phosphorylation Efficiency of Potato Tuber Mitochondria Respiring Exogenous NADH, as Compared With Succinate Activities

\begin{tabular}{llcc}
\hline Substrate & Divalent cation & $\begin{array}{c}\text { Phosphorylation } \\
\text { activity }(\%)\end{array}$ & $\Delta \psi(\mathrm{mV})$ \\
\hline Succ. & $\mathrm{Mg}^{2+}$ & 100 & -215 \\
“ & - & 93 & -213 \\
NADH & $\mathrm{Mg}^{2+}+\mathrm{Ca}^{2+}$ & 87 & -222 \\
" & $\mathrm{Ca}^{2+}$ & 61 & -215 \\
“ & $\mathrm{Mg}^{2+}$ & 30 & -208 \\
“ & - & 22 & -210 \\
& - +EDTA & nd & -166 \\
\hline
\end{tabular}

Note. Relative phosphorylation activities, in percentage, and $\Delta \psi$ values after phosphorylations. Maximal activity, referred as $100 \%$ was obtained for succinate-dependent respiration with $0.25-\mathrm{mM} \mathrm{Mg}^{2+}$, corresponding to $612 \mathrm{nmol}$ ADP phosphoylated. mg protein ${ }^{-1}$. $\mathrm{min}^{-1}$. Results obtained from $\mathrm{TPP}^{+}$-electrode records of $100-\mu \mathrm{M}$ ADP phosphorylated with additions of $\mathrm{Mg}^{2+}(0.25 \mathrm{mM})$ and $\mathrm{Ca}^{2+}$ $(0.25 \mathrm{mM})$, as indicated. Assays were produced in conditions expressed in Materials and Methods. Results are representative of a group of at least three independent experiments.

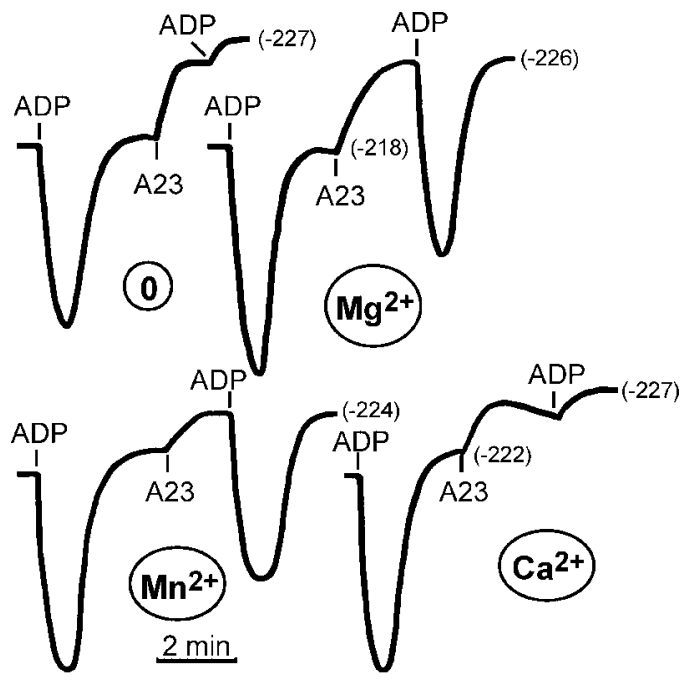

Fig. 7. Compared regulation of succinate-dependent respiration by $\mathrm{Mg}^{2+}, \mathrm{Mn}^{2+}$, and $\mathrm{Ca}^{2+}$. $\mathrm{TPP}^{+}$-electrode phosphorylation records, before and after A23 addition, in the absence (control) and presence of 0.25 $\mathrm{mM} \mathrm{Mg}^{2+}, \mathrm{Mn}^{2+}$, or $\mathrm{Ca}^{2+}$. Assays were performed as indicated in Fig. 5 . Numbers within parentheses state $\Delta \psi$ values in mV. All the phosphorylations are with $100-\mu \mathrm{M}$ ADP. A23, addition of $1 \mu \mathrm{M}$ A23187. Records are representative of a group of at least three independent experiments.

electrode only detects $\Delta \psi$ ). Further ADP addition induces a small cumulative increase, indicating full inhibition of phosphorylation by A23. This was also observed when $\mathrm{Ca}^{2+}(0.25 \mathrm{mM})$ was added, showing that this cation does not replace $\mathrm{Mg}^{2+}$ in its requirement for the phosphorylation system. In contrast, $\mathrm{Mn}^{2+}$ can replace $\mathrm{Mg}^{2+}$, showing almost the same phosphorylation rate (Fig. 7) and succinate dehydrogenase activities.

In the presence of $\mathrm{A} 23$ and absence of external $\mathrm{Mg}^{2+}$, $\mathrm{Ca}^{2+}(0.25 \mathrm{mM})$ neither dissipates $\Delta \psi$ (Fig. 7) nor significantly stimulates state 4 respiration, at variance with results in rat liver mitochondria, where $\Delta \psi$ was dissipated simultaneously with strong stimulation of $\mathrm{O}_{2}$ consumption (>300\%) (Panov and Scarpa, 1996b; Reed and Lardy, 1972). These effects were avoided by ruthenium red (RR), a noncompetitive inhibitor of the animal mitochondrial $\mathrm{Ca}^{2+}$ uniporter (Reed and Bygrave, 1974) or by EGTA, a $\mathrm{Ca}^{2+}$ chelator, showing that they are caused by $\mathrm{Ca}^{2+}$ movements across the mitochondrial membranes. However, the absence of those effects in potato tuber mitochondria confirm nonexistence of similar $\mathrm{Ca}^{2+}$ movements across the mitochondrial membranes (Chen and Lehninger, 1973), making it easier to discern $\mathrm{Mg}^{2+}$ action.

Even for $\alpha$-ketoglutarate and malate/pyruvate dehydrogenases, after addition of A23 (in the presence of $1-\mathrm{mM} \mathrm{Mg}^{2+}$ and 0.5-mMEGTA), we never observed stimulation by $\mathrm{Ca}^{2+}(0.1-0.5 \mathrm{mM})$ instead of $\mathrm{Mg}^{2+}$ (results not shown), suggesting that $\mathrm{Ca}^{2+}$ (or at least free $\mathrm{Ca}^{2+}$ ) 
is not required at all for those plant dehydrogenase activities. However, our results of potato tuber mitochondria, are not in contrast with results for known $\mathrm{Ca}^{2+}$-sensitive dehydrogenases of animal (McCormack et al., 1990; McCormack and Denton, 1979; Panov and Scarpa, 1996a) and plant mitochondria (Coultate and Dennis, 1969; Turano, 1998), because our experiments were produced in conditions different from the other authors.

In summary, conclusions about the regulatory role of $\mathrm{Mg}^{2+}$ on potato tuber mitochondrial respiration are: 1) activities of the several respiratory substrates were significantly enhanced by external (without A23) and mitochondrial matrix $\mathrm{Mg}^{2+}$; 2) higher levels of $\mathrm{Mg}^{2+}$ are required inside than outside the mitochondria for maximal state 3 activity, with different requirements of $\mathrm{Mg}^{2+}$ for the several substrates; 3 ) no respiration of $\alpha$-ketoglutarate was detected in the absence of external $\mathrm{Mg}^{2+}$, which revealed essential for the substrate transport, unlike citrate and malate dependent-respiration, however, both required internal $\mathrm{Mg}^{2+}$; 4) the phosphorylation system, which is used by all the respiratory substrates, is efficient at low mitochondrial matrix $\mathrm{Mg}^{2+}(0.25-\mathrm{mM})$ as judged for succinate activities, but high rates of Complex I-dependent phosphorylation were only obtained with higher $\mathrm{Mg}^{2+}$ concentrations (at least 4-mM), demonstrating that high levels of $\mathrm{Mg}^{2+}$ are required for high Complex I-dependent dehydrogenase activities, rather than for the phosphorylation system itself.

Preliminary results obtained with turnip (Brassica napus L.) and sweet potato (Ipomoea batatas L.) indicate a similar qualitative regulatory role of the divalent cations (results not shown).

\section{ACKNOWLEDGMENTS}

This work was supported by IMAR-Instituto do Mar. Experimental work was also financed by the grant ICCTI:4.1.3/FAPESP. We thank Dr Leonardo Vicente for informatic assistance.

\section{REFERENCES}

Beavis, A. D., and Garlid, K. D. (1987). J. Biol. Chem. 262, 1508515093.

Beavis, A. D., and Vercesi, A. E. (1992). J. Biol. Chem. 267, 30793087.

Bedino, S., and Testore, G. (1992). Int. J. Biochem. 24, 1697-1704.

Bernardi, P. (1999). Physiol. Rev. 79, 1127-1155.

Bowman, E. J., and Ikuma, H. (1976). Plant Physiol. 58, 433-437.

Bradford, M. M. (1976). Anal. Biochem. 72, 248-264.

Bulygin, V. V., Syroeshkin, A. V., and Vinogradov, A. D. (1993). FEBS Lett. 328, 193-196.

Cadenas, S., and Brand, M. D. (2000). Biochem. J. 348, 209-213.

Chen, C.-H., and Lehninger, A. L. (1973). Arch. Biochem. Biophys. 157, 183-196.

Corkey, B. E., Duszynski, J., Rich, T. L., Matschinsky, B., and Williamson, J. R. (1986). J. Biol. Chem. 261, 2567-2574.

Coultate, T. P., and Dennis, D. T. (1969). Eur. J. Biochem. 7, 153-158.

Flatman, P. W. (1984). J. Membr. Biol. 80, 1-14.

Gómez-Puyou, A., Ayala, G., Muller, U., and Gómez-Puyou, M. T. (1983). J. Biol. Chem. 258, 13673-13679.

Jung, D. W., Panzeter, E., Baysal, K., and Brierley, G. P. (1997). Biochim. Biophys. Acta 1320, 310-320.

Kamo, N., Muratsugu, M., Hongoh, R., and Kobatake, Y. (1979). J. Membr. Biol. 49, 105-121.

McCormack, J. G., and Denton, R. M. (1979). Biochem. J. 180, 533544.

McCormack, J. G., Halestrap, A., and Denton, R. M. (1990). Physiol. Rev. 70, 391-425.

Moravec, C. S., and Bond, M. (1991). Am. J. Physiol. 260, H989H997.

Moravec, C. S., and Bond, M. (1992). J. Biol. Chem. 267, 5310-5316.

Neuburger, M., Journet, E.-P., Bligny, R., Carde, J.-P., and Douce, R. (1982). Arch. Biochem. Biophys. 217, 312-323.

Panov, A., and Scarpa, A. (1996a). Biochemistry 35, 427-432.

Panov, A., and Scarpa, A. (1996b). Biochemistry 35, 12849-12856.

Pfeiffer, D. R., Reed, P. W., and Lardy, H. A. (1974). Biochemistry 13, 4007-4014.

Reed, K. C., and Bygrave, F. L. (1974). Biochem. J. 140, 143-150.

Reed, P. W., and Lardy, H. A. (1972). J. Biol. Chem. 247, 6970-6977.

Romani, A., Dowell, E., and Scarpa, A. (1991). J. Biol. Chem. 266, 24376-24384.

Romani, A., Marfella, C., and Scarpa, A. (1993). J. Biol. Chem. 268 , $15489-15495$.

Soole, K. L., Dry, I. B., and Wiskich, J. T. (1990). Physiol. Plant 87 , 205-210.

Thomas, A. P., Diggle, T. A., and Denton, R. M. (1986). Biochem. J. 238, 83-91.

Tobin, A., Djerddjour, B., Journet, E., Neuburger, M., and Douce, R. (1980). Plant Physiol. 66, 225-229.

Turano, F. J. (1998). Physiol. Plant 104, 337-344. 